\title{
Comparative study of Time Optimal Controller with PID Controller for a Continuous Stirred Tank Reactor
}

\author{
Ayush Sharma, Miroslav Fikar, Monika Bakošová \\ Faculty of Chemical and Food Technology \\ Slovak University of Technology in Bratislava \\ 81237 Bratislava, Slovakia \\ ayush.sharma@stuba.sk
}

\begin{abstract}
Continuous Stirred Tank Reactor (CSTR) is the productive part in different chemical and process industries, and hence there is a need to control this process at desired optimum conditions of temperature and concentration. This paper deals with modelling and constrained control of a CSTR that minimises the processing time. Modelling consisted in performing the mass and heat balances of the CSTR system. Different controllers (time optimal, PID) were then applied to this non-linear system and compared within the boundaries of the control input and states. A theoretical case study was solved numerically using the orthogonal collocations method and simulations, resulting in a comparison of different controllers.
\end{abstract}

Keywords: CSTR, mathematical modelling, constrained optimisation, PID control, time optimal control

\section{Introduction}

CSTR is a very important part of chemical and process industries. The CSTR configuration is widely used in industrial applications and in wastewater treatment units (i.e. activated sludge reactors). As mentioned in (Pathak, Markana and Parikh, 2010), it is very difficult to control this non-linear process. One of the main reasons of this difficulty in control is the uncertainty in chemical kinetics, multiple steady states and non-linear behaviour. In this paper, the simplest form of reaction, i.e. irreversible conversion of a single reactant to a single product is studied and discussed. A comparison of different controllers was presented in (Allwin, Biksha, Abirami, Kala and Udhaya, 2014) as a comparative study of a conventional PID controller and Model Predictive Control (MPC). This study proved MPC to be more suitable for the control of a CSTR. In another comparative study (Shakib, 2013) of PI, PID, and a reset controller, a linearized model was used to study and control the process. Disturbance rejection and the integral error criterion were used to compare different controllers and the reset controller was found to be the best one according to these criteria.

In another research work (Pathak, Markana and Parikh, 2010), non-linear MPC was implied to assist the optimal control of a CSTR. The simulation studies in this paper proved non-linear MPC to be a better alternative for conventional controllers. The time optimal control problem for a jacket cooled CSTR with an exothermic, irreversible, second-order, homogeneous, liquid-phase reaction (saponification of ethyl acetate) was solved in (Javensky and
Kadlec, 1970) with the maximum principle and phase plane analysis. Both experimental studies and analogue computer simulation studies were conducted, but the results were not very satisfying. In another paper (Kim. H. J et al., 1998), a successful implementation of time optimal control for copolymerisation of methyl metacrylate and methyl acrylate was studied. Minimum principle of the optimal control theory was applied to achieve the copolymerisation in minimum time, but no comparison with other possible controllers was studied. The mentioned papers present the reason to keep searching for alternative controllers for such nonlinear complex processes. Optimal control is a vast area of control theory, while time minimisation is a part of this theory, and it is the mode of control which is compared with PID control in this paper.

This paper investigated the control of a jacketed CSTR as seen in Fig. 1. The flow rate of the coolant was the control variable and was constrained between two boundaries. The reactor temperature was the controlled output, and it was constrained between the upper and the lower boundary, too. The aim was to study the control and states behaviour in order to minimise the control time when different, i.e. time optimal and PID based controllers were applied to control an irreversible single reactant, single product reaction.

\section{Theoretical}

In this section, the process and reaction to be controlled are briefly described, and the theoretical aspects of time optimal control are discussed. 


\section{Process model}

In this study, an irreversible, single reactant, single product reaction was assumed according to the equation:

$$
\mathrm{A} \rightarrow \mathrm{B}
$$

The process operation, mass flows and heat flows are presented in Fig. 1. Feed consisting of reactant A was fed continuously at the flow rate $F$ with reactant $\mathrm{A}$ concentration $c_{\mathrm{A} \text {,in }}$ at temperature $T_{0}$. The coolant was fed into the jacket at the flow rate $F_{\mathrm{J}}$, and the temperature $T_{\mathrm{c} \text {,in }}$. The first-order exothermic reaction inside the CSTR ran according to Eq. (1), and the outlet stream contained reactant A having concentration $c_{\mathrm{A}}$, and the product $\mathrm{B}$ having concentration $c_{\mathrm{B}}$.

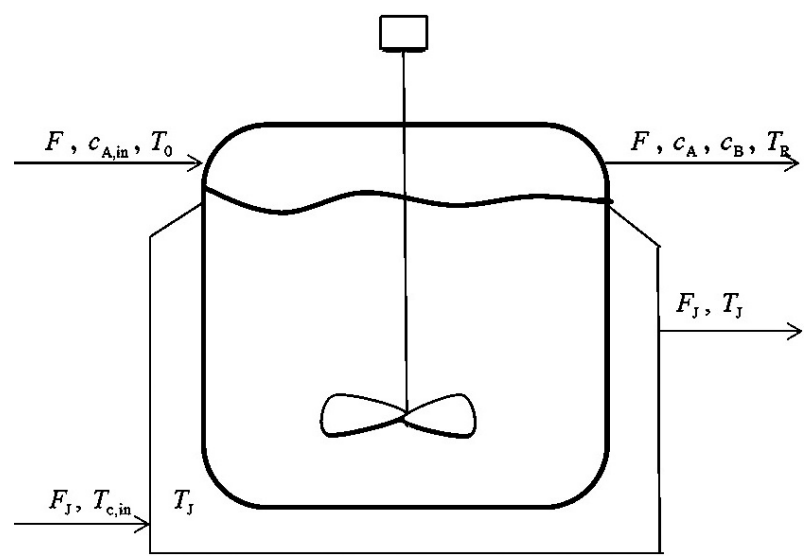

Fig. 1. Process scheme of the CSTR.

The CSTR was operated at a constant volume, i.e. $V_{\mathrm{R}}$ was constant, and hence the flow rate of the outlet stream equalled $F$, and similarly the flow rate of coolant leaving the jacket was equal to flow rate coming into the jacket, i.e. $F_{\mathrm{J}}$.

The state variables $c_{\mathrm{A}}, c_{\mathrm{B}}, T_{\mathrm{R}}$ and $T_{\mathrm{J}}$ are the concentration of $\mathrm{A}$ and $\mathrm{B}$ inside the CSTR, temperature inside the CSTR, and temperature inside the jacket, respectively. The flow inside the jacket $F_{\mathrm{J}}$ was the control variable. The first order reaction rate is given as

$$
v=k c_{\mathrm{A}}=c_{\mathrm{A}} k_{0} \mathrm{e}^{\frac{-E}{R T_{\mathrm{R}}}}
$$

where, $v$ is the rate of consumption of reactant $\mathrm{A}, k$ is the specific reaction rate, $k_{0}$ is the preexponential factor, $E$ represents the activation energy, and $R$ is the gas constant. The reactor dynamics was modelled by exploiting the mass and heat balances of the reactor, and the heat balance of the jacket providing the dynamic non-linear model as follows:

$$
\frac{\mathrm{d} c_{\mathrm{A}}}{\mathrm{d} t}=\frac{F}{V_{\mathrm{R}}}\left(c_{\mathrm{A}, 0}-c_{\mathrm{A}}\right)-c_{\mathrm{A}} k_{0} \mathrm{e}^{\frac{-E}{R \mathrm{~T}_{\mathrm{R}}}}
$$

$$
\begin{gathered}
\frac{\mathrm{d} c_{\mathrm{B}}}{\mathrm{d} t}=-\frac{F}{V_{\mathrm{R}}} c_{\mathrm{B}}+c_{\mathrm{A}} k_{0} \mathrm{e}^{\frac{-E}{R T_{\mathrm{R}}}} \\
\frac{\mathrm{d} T_{\mathrm{R}}}{\mathrm{d} t}= \\
=\frac{F}{V_{\mathrm{R}}}\left(T_{0}-T_{\mathrm{R}}\right)-\frac{\Delta_{r} H c_{\mathrm{A}} k_{0} \mathrm{e}^{\frac{-E}{R T_{\mathrm{R}}}}}{\rho c_{P}}-\frac{U a_{\mathrm{J}}\left(T_{\mathrm{R}}-T_{\mathrm{J}}\right)}{V_{\mathrm{R}} \rho c_{P}} \\
\frac{\mathrm{d} T_{\mathrm{J}}}{\mathrm{d} t}=\frac{F_{\mathrm{J}}}{V_{\mathrm{J}}}\left(T_{\mathrm{c}, \text { in }}-T_{\mathrm{J}}\right)-\frac{U a_{\mathrm{J}}\left(T_{\mathrm{R}}-T_{\mathrm{J}}\right)}{V_{\mathrm{J}} \rho_{\mathrm{J}} c_{P, \mathrm{~J}}}
\end{gathered}
$$

where $\Delta_{r} H$ is the heat of the reaction, $\rho$ is the density of the reactant and product (density of the reaction mixture is assumed to be constant), $\rho_{\mathrm{J}}$ is the density of the coolant, and $c_{\mathrm{P}}$ is the specific heat of the reactant and product, while $c_{P, \mathrm{~J}}$ is the specific heat of the coolant.

\section{Process optimisation}

In this section, a brief description of the optimisation/minimisation problem is presented. The aim was to minimise the reaction time of the reaction given in Eq. (1), while controlling the process to a steady state. The minimisation problem or objective function to minimise time can be formulated as

$$
\begin{gathered}
J^{*}=\min _{F_{\mathrm{J}}(t)} \int_{0}^{t_{\mathrm{f}}} 1 . \mathrm{d} t \\
\text { s.t. }(3 \mathrm{a})-(3 \mathrm{~d}) \\
c_{\mathrm{A}}(0)=c_{\mathrm{A}, 0}, c_{\mathrm{B}}(0)=c_{\mathrm{B}, 0}, T_{\mathrm{R}}(0)=T_{\mathrm{R}, 0}, T_{\mathrm{J}}(0)=T_{\mathrm{J}, 0} \\
c_{\mathrm{A}}\left(t_{\mathrm{f}}\right)=c_{\mathrm{A}, \mathrm{f}}, c_{\mathrm{B}}\left(t_{\mathrm{f}}\right)=c_{\mathrm{B}, \mathrm{f}}, T_{\mathrm{R}}\left(t_{\mathrm{f}}\right)=T_{\mathrm{R}, \mathrm{f}}, T_{\mathrm{J}}\left(t_{\mathrm{f}}\right)=T_{\mathrm{J}, \mathrm{f}} \\
\dot{c_{\mathrm{A}}}\left(t_{\mathrm{f}}\right)=0, \dot{c_{\mathrm{B}}}\left(t_{\mathrm{f}}\right)=0, \dot{T}_{\mathrm{R}}\left(t_{\mathrm{f}}\right)=0, \dot{T}_{\mathrm{J}}\left(t_{\mathrm{f}}\right)=0 \\
F_{\mathrm{J}} \in\left[F_{\mathrm{J}, \min }, F_{\mathrm{J}, \max }\right], T_{\mathrm{R}} \in\left[T_{\mathrm{R}, \min }, T_{\mathrm{R}, \max }\right]
\end{gathered}
$$

where $t_{\mathrm{f}}$ is the optimisation terminal/final time, $\dot{c}_{\mathrm{A}}, \dot{c}_{\mathrm{B}}, \dot{T}_{\mathrm{R}}$, and $\dot{T}_{\mathrm{J}}$ represent the derivatives of state variables w.r.t. time, i.e. the left hand sides of the dynamic equations (3a), (3b), (3c) and (3d), respectively. To control the process at steady state, these derivatives, i.e. $\dot{c}_{\mathrm{A}}, \dot{c}_{\mathrm{B}}, \dot{T}_{\mathrm{R}}$, and $\dot{T}_{\mathrm{J}}$ should be equal to 0 at final time of optimisation, i.e. at $t_{\mathrm{f}}$. Numerical optimisation of such a problem is discussed in the next section, i.e. Experimental.

Minimisation of time in the optimal control theory (OCP) as studied by (Hull 2003) is historically the first optimal control problem to be treated, and it aims at finding such a control trajectory that drives the process from the given initial state to a 
fixed final state in minimum time within the constraints. OCP can be distinguished e.g. by fixed/ free initial/terminal time/state as mentioned in (Hull, 2003). Initial time is usually fixed since it is the time when we start to control the process, and we have considered it to be equal to 0 . For such constrained problems, the control trajectory is either the bang-bang control, i.e. only the boundary values of control, or a singular arc and thus some other value/values of control along with boundary values.

\section{Experimental}

Here, a literature case study taken from (Luyben 2007) is solved using different controllers. The values of different CSTR parameters are given in Table 1. First, the steady state analysis of the process is presented. To find the steady states, heat in/ out $(Q)$, and heat generated $\left(Q_{\text {gen }}\right)$ were analysed by checking the effect of 100 different values of the steady state reactor temperature $T_{\mathrm{R}}^{\mathrm{s}}$ within the constrained range of $T_{\mathrm{R}} \in[280,480] \mathrm{K}$, with $F_{\mathrm{J}}^{\mathrm{s}}=0.004377 \mathrm{~m}^{3} \cdot \mathrm{s}^{-1}$, and the following equations generated by the heat balance

$$
\left.Q=F \rho c_{P}\left(T_{\mathrm{R}}^{\mathrm{s}}-T_{0}\right)+U a_{\mathrm{J}}\left(T_{\mathrm{R}}^{\mathrm{s}}-T_{\mathrm{J}}^{\mathrm{s}}\right)\right]
$$

and

$$
Q_{\text {gen }}=-V_{\mathrm{R}} \Delta_{r} H c_{\mathrm{A}}^{\mathrm{s}} k_{0} \mathrm{e}^{\frac{-E}{R T_{\mathrm{R}}^{\mathrm{s}}}}
$$

The steady values of states $c_{\mathrm{A}}^{\mathrm{s}}$ and $T_{\mathrm{J}}^{\mathrm{s}}$ were calculated by equating the left hand sides of Eqs. (3a) and (3d) to 0 . Fig. 2 shows the trend of $Q$ and $Q_{\text {gen }}$, as the temperature of the reactor $T_{\mathrm{R}}^{\mathrm{s}}$ was increased. It is
Tab. 1. CSTR parameters for irreversible exothermic reaction (from (Luyben, 2007)).

\begin{tabular}{lcc}
\hline Parameter & value & unit \\
\hline Preexponential factor & 20750000 & $\mathrm{~s}^{-1}$ \\
Activation energy & 69710000 & $\mathrm{~J} \cdot \mathrm{kmol}^{-1}$ \\
Process density & 801 & $\mathrm{~kg} \cdot \mathrm{m}^{-3}$ \\
Coolant density & 1000 & $\mathrm{~kg} \cdot \mathrm{m}^{-3}$ \\
Heat capacity & 3137 & $\mathrm{~J} \cdot \mathrm{kg}^{-1} \cdot \mathrm{K}^{-1}$ \\
Coolant heat capacity & 4183 & $\mathrm{~J} \cdot \mathrm{kg}^{-1} \cdot \mathrm{K}^{-1}$ \\
Heat of reaction & -69710000 & $\mathrm{~J} \cdot \mathrm{kmol}^{-1}$ \\
Feed temperature & 294 & $\mathrm{~K}$ \\
Feed flowrate & 0.004377 & $\mathrm{~m} \cdot \mathrm{s}^{-1}$ \\
Feed concentration & 8.01 & $\mathrm{kmol} \cdot \mathrm{m}^{-3}$ \\
Coolant inlet temperature & 294 & $\mathrm{~K}$ \\
Overall heat transfer coefficient & 851 & $\mathrm{~W} \cdot \mathrm{K}^{-1} \cdot \mathrm{m}^{-2}$ \\
Gas constant & 8314 & $\mathrm{~J} \cdot \mathrm{K}^{-1} \cdot \mathrm{kmol}^{-1}$ \\
Reactor volume & 5 & $\mathrm{~m}{ }^{3}$ \\
Coolant flowrate & Control & $\mathrm{m}^{3} \cdot \mathrm{s}^{-1}$ \\
Aspect ratio (Length/Diameter) & 2 & - \\
\hline
\end{tabular}

Tab. 2. Three steady states observed for the given parameters.

\begin{tabular}{cccc}
\hline Steady state & $c_{\mathrm{A}}^{\mathrm{s}}\left[\mathrm{kmol} . \mathrm{m}^{-3}\right]$ & $T_{\mathrm{R}}^{\mathrm{s}}[\mathrm{K}]$ & $T_{\mathrm{J}}^{\mathrm{s}}[\mathrm{K}]$ \\
\hline 1 & 7.92 & 295.5 & 294.6 \\
2 & 5.12 & 342.8 & 312.9 \\
3 & 0.11 & 427.2 & 345.6 \\
\hline
\end{tabular}

evident from the figure that there are three steady states, as there are three points where $Q=Q_{\text {gen }}(\mathrm{Ta}$ ble 2).

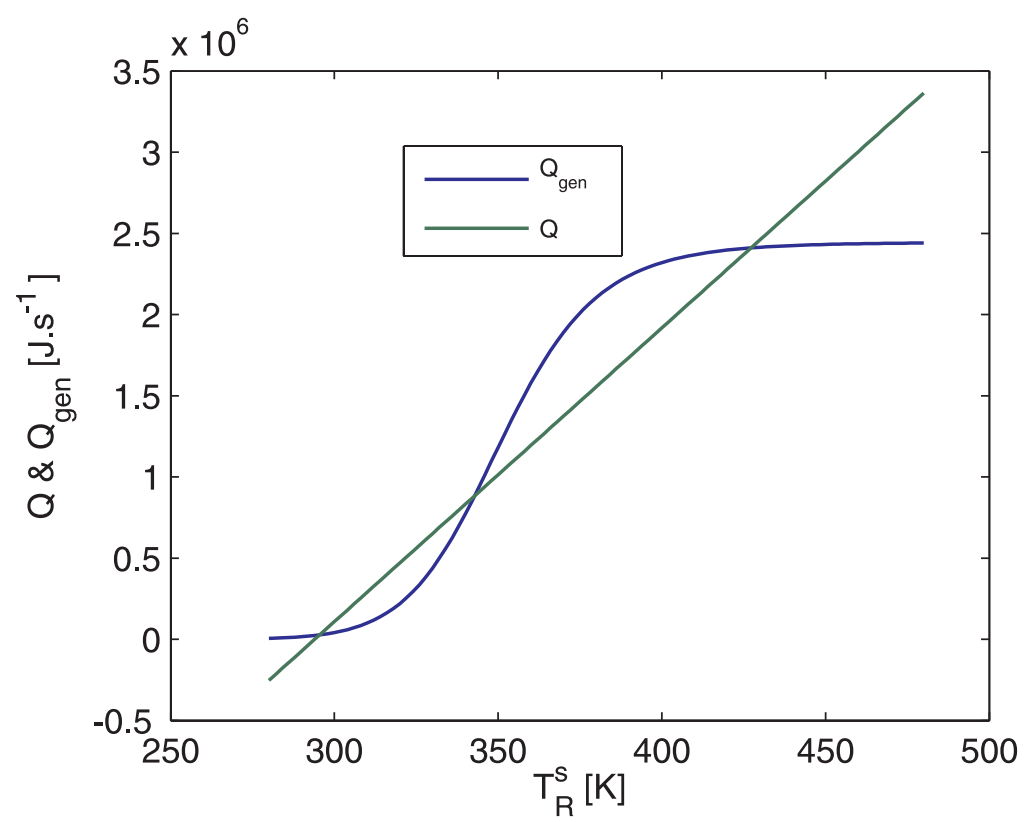

Fig. 2. Change in $Q$ and $Q_{\text {gen }}$ with the increasing reactor temperature. 


\section{Time optimal control}

The case study described above is solved here for the purpose of time minimisation with the aid of the numerical method of orthogonal collocations implemented in (Čižniar, Fikar, and Latifi, 2005) as a toolbox called Dynopt. The aim was to find the control trajectory, to go from the prescribed initial state of the reactor, i.e. $\left[c_{\mathrm{A}, 0}, c_{\mathrm{B}, 0}, T_{\mathrm{R}, 0}, T_{\mathrm{J}, 0}\right]=[3$ $\left.\mathrm{kmol} . \mathrm{m}^{-3}, 1 \mathrm{kmol} . \mathrm{m}^{-3}, 380 \mathrm{~K}, 310 \mathrm{~K}\right]$, to the conversion of $\mathrm{A}$ to the third steady state concentration of $0.11 \mathrm{kmol} . \mathrm{m}^{-3}$ while staying within the constrained control $F_{\mathrm{J}} \in[0.0004377,0.04377] \mathrm{m}^{3} \cdot \mathrm{s}^{-1}$ and constrained reactor temperature $T_{\mathrm{R}} \in[280,480] \mathrm{K}$. Briefly, the objective was to aid the conversion of $\mathrm{A}$ from $3 \mathrm{kmol} . \mathrm{m}^{-3}$ to $0.11 \mathrm{kmol} . \mathrm{m}^{-3}$, and the reactor temperature to the third steady state value, i.e. $T_{\mathrm{R}}^{\mathrm{s}}=$ $427.2 \mathrm{~K}$ with a $\pm 0.3 \mathrm{~K}$ error margin, in minimum time and within the constrained boundaries of control $F_{\mathrm{J}}$ and state $T_{\mathrm{R}}$.

The optimisation was done for different numbers of affine periods, but the optimal control trajectory was found to be of the bang-bang type. The control trajectory was divided into two piecewise constant values with the upper boundary, i.e. $0.04377 \mathrm{~m}^{3} . \mathrm{s}^{-1}$ for the first time period of $209 \mathrm{~s}$, and the lower boundary value of $0.0004377 \mathrm{~m}^{3} . \mathrm{s}^{-1}$ for the second time period of $678 \mathrm{~s}$. The allowed error margin for stability or steady state value of $T_{\mathrm{R}}$ was considered to be $\pm 0.3 \mathrm{~K}$, and hence the time optimal control required $887 \mathrm{~s}$ to achieve these results.
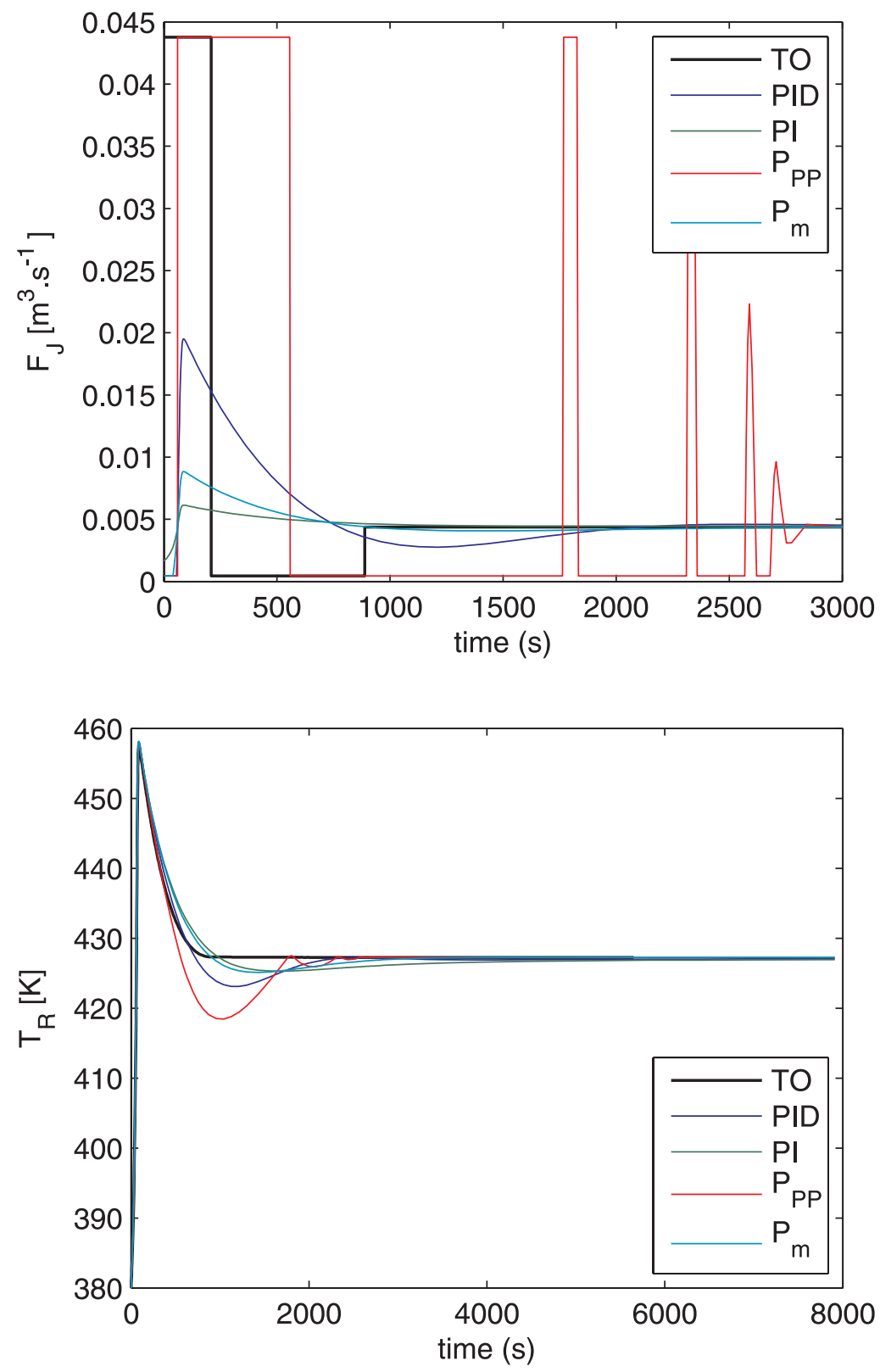

Fig. 3. Trajectory of control $\left(F_{\mathrm{J}}\right)$ and reactor temperature $\left(T_{\mathrm{R}}\right)$ with time optimal (TO) and different PID based controllers. 


\section{Comparison of controllers}

In this section, the described case study was controlled using classical PID controllers. Reactor temperature was the controlled variable, and the PID was designed using the MATLAB toolbox. The transfer function to design the controller was evaluated from multiple step responses of the CSTR s-function in MATLAB, and then the system identification toolbox PIDDESIGN (Oravec and Bakošová, 2012), implementable in MATLAB, was used. The controller parameters are given in Table 3. In Fig. 3, a comparison of different controllers, i.e.

1. PID designed using MATLAB tool,

2. PI designed using MATLAB tool,

3. $\mathrm{P}\left(\mathrm{P}_{\mathrm{PP}}\right)$ designed using Pole placement method,

4. $\mathrm{P}\left(\mathrm{P}_{\mathrm{m}}\right)$ designed using MATLAB tool, and

5. TO time optimal control

is depicted. It is evident from Fig. 3 that of all the controllers, time optimal control (TO) required the minimum time to reach the steady state within the allowed error margin range of the steady state reactor temperature $T_{\mathrm{R}}^{\mathrm{s}}=427.2 \mathrm{~K}$, and the time optimal is the only controller without any undershoot (temperature not decreasing below the steady state once reached). PID based controllers showed a similar trajectory although the time to settle down was longer than the time optimal controller. PID and $\mathrm{P}_{\mathrm{PP}}$ controller's settling time was the shortest of the classical controllers, but the trajectory of control $F_{\mathrm{J}}$ and the state $T_{\mathrm{R}}$ for $\mathrm{P}_{\mathrm{PP}}$ was oscillating. $\mathrm{PI}$ and $\mathrm{P}_{\mathrm{m}}$ gave smoother results with respect to the reactor temperature and the control trajectory $\left(F_{\mathrm{J}}\right)$ as no substantial under-shooting was observed in either of them when compared to PID and $\mathrm{P}_{\mathrm{PP}}$, but settling time in both was longer.

Tab. 3. Controller parameters.

\begin{tabular}{lccc}
\hline Controller & $\mathrm{K}_{\mathrm{P}}$ & $\mathrm{K}_{\mathrm{I}}$ & $\mathrm{K}_{\mathrm{D}}$ \\
\hline PID & -0.00049 & 5998.2 & 0.105 \\
PI & -0.00006 & 2118.8 & - \\
$\mathrm{P}_{\mathrm{PP}}$ & -0.51588 & - & - \\
$\mathrm{P}_{\mathrm{m}}$ & -0.00015 & - & - \\
\hline
\end{tabular}

PI gave quite smooth results in context of the reactor temperature, but it required the longest time to reach the steady state (Fig. 3). The P controller designed using the pole placement method $\left(\mathrm{P}_{\mathrm{PP}}\right)$ provided oscillating results (Fig. 3), but required shorter time than other PID controllers to reach the third steady state. Fig. 4 again proves that the time optimal control (TO) required the shortest time for the jacket temperature to reach a steady value, without any over-shooting, followed by $\mathrm{P}_{\mathrm{PP}}, \mathrm{P}_{\mathrm{m}}$, PID, and PI.

Tab. 4. Time required by different controllers to reach the steady state within the error range of $\pm 0.3 \mathrm{~K}$ at $T_{\mathrm{R}}{ }^{\mathrm{s}}=427.2 \mathrm{~K}$.

\begin{tabular}{lc}
\hline Controller & $t_{\mathrm{T}}[\mathrm{s}]$ \\
\hline TO & 887 \\
PID & 2386 \\
PI & 18232 \\
$\mathrm{P}_{\mathrm{PP}}$ & 2450 \\
$\mathrm{P}_{\mathrm{m}}$ & 3400 \\
\hline
\end{tabular}

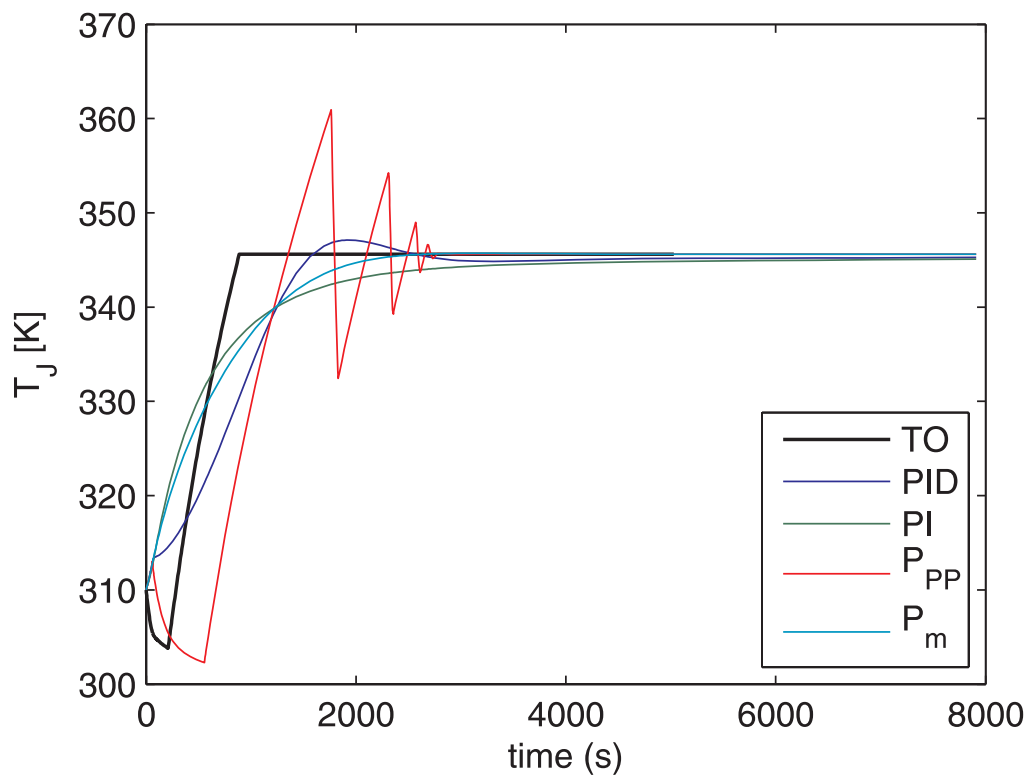

Fig. 4. Trajectory of jacket temperature $\left(T_{\mathrm{J}}\right)$ with time optimal (TO) and different PID based controllers. 


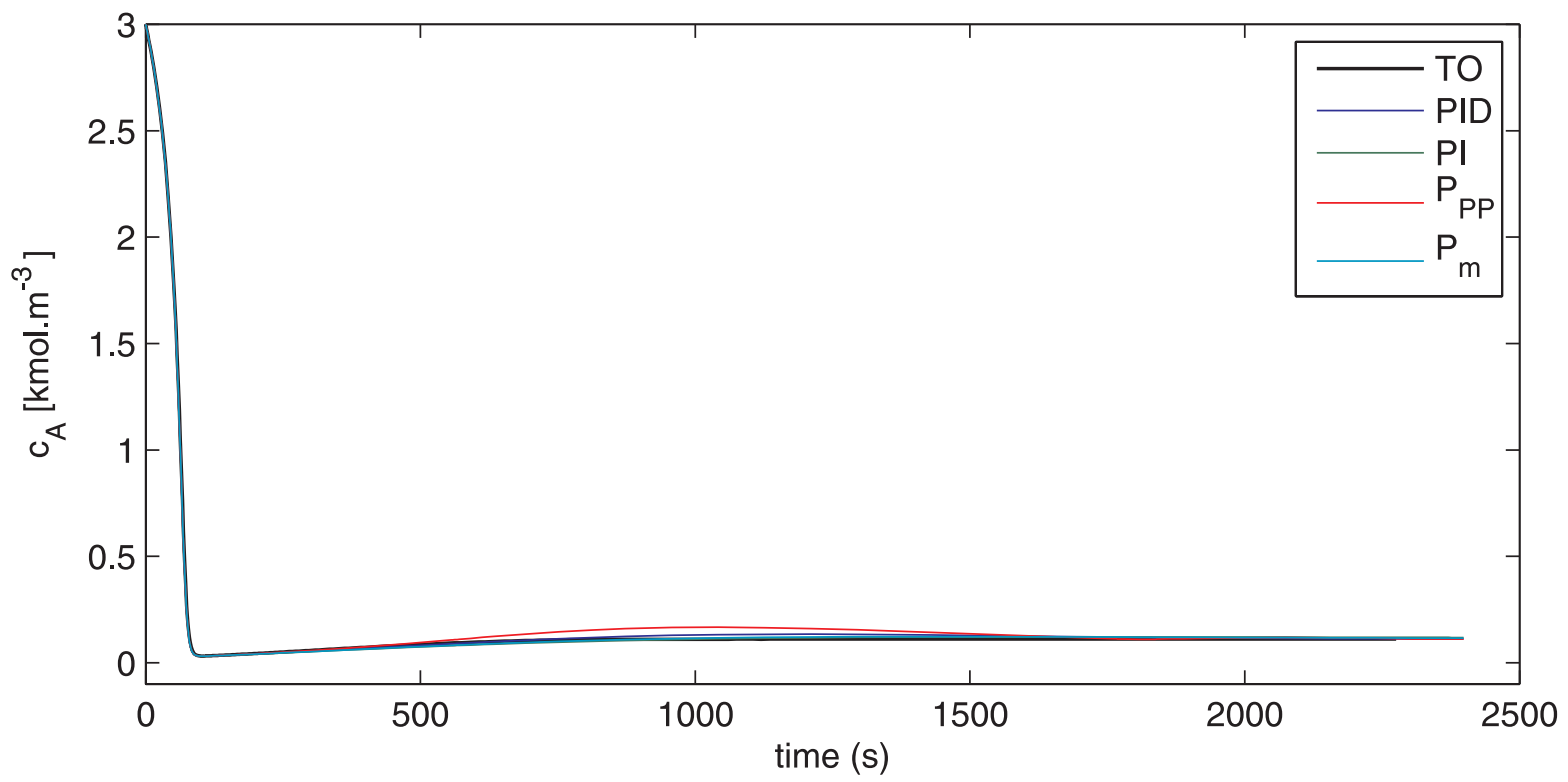

b

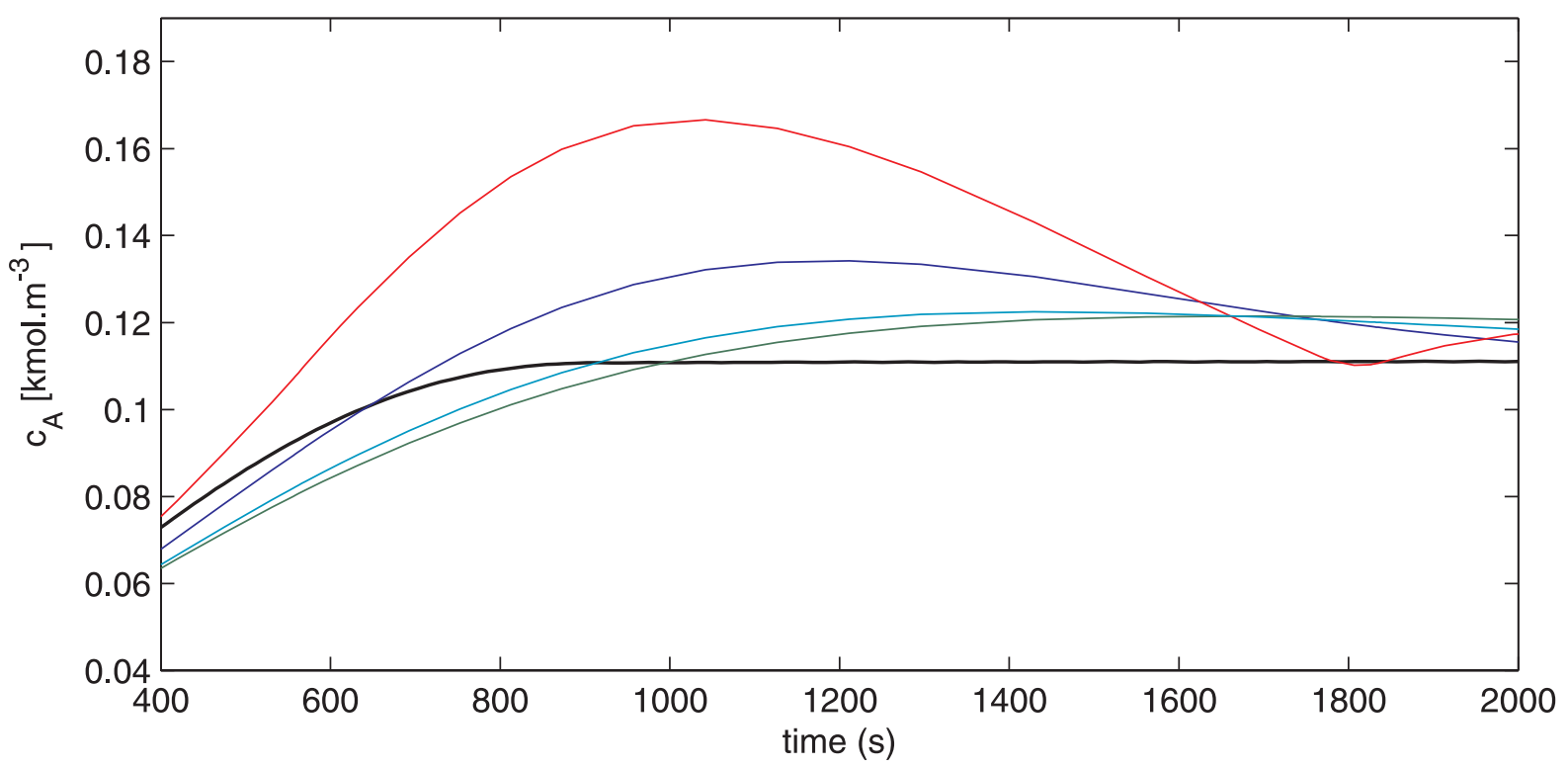

Fig. 5. Trajectory of reactant A concentration $\left(c_{\mathrm{A}}\right)$ with time optimal (TO) and different PID based controllers.

The time required to reach the third steady state reactor temperature by classical controllers designed in this paper, when compared to the time required by time optimal control from Table 4 , acts as the distinguishing point between all controllers as the objective of the case study was to reach the third steady state in minimum time. The control trajectory for the time optimal control comprises of two piecewise constant values, and both being on the boundary of allowed control. In Fig. 5, the trajectory of reactant A concentration is presented and compared for different controllers. As it can be seen in Fig. 5a, all controllers are able to bring the concentration of reactant $A$ to the desired steady state value. Fig. 5b provides a zoom of Fig. 5a for better comparison. It is clear that the time optimal (TO) control required the minimum time to reach the objective.

\section{Conclusions}

In this paper, the time optimal control to achieve a specified conversion of a single reactant, single product, irreversible non-linear CSTR has been studied. The time optimal controller has been compared to classical PID based controllers. Mathematical modelling of the system was done using mass and heat balances. A literature case study was then solved numerically to find the time optimal control of this process and the bang-bang type 
control with only upper and lower boundary values was identified as the most suitable. The same case study was then controlled with PID, PI and P controllers. The process was controlled to the steady state reactor temperature but these controllers required more time than the time optimal control to reach this steady state. Time required to reach the desired concentration of the reactant was compared with that of the time optimal control, and the time optimal control proved to be the best of the studied controllers to achieve the objective of this study.

\section{Acknowledgement}

This publication is the result of the Research E Development Operational Programme for the project University Scientific Park STU in Bratislava, ITMS 26240220084 , supported by the Research E Development Operational Programme funded by the ERDF

\section{References}

Allwin S, Biksha NS, Abirami S, Kala H, Udhaya PA (2014) Comparison of Conventional Controller with Model Predictive Controller for CSTR Process. International Journal of Advanced Research in Electrical, Electronics and Instrumentation Engineering. 3(9): 11934-11941.
Čižniar M, Fikar M, and Latifi AM (2005) MATLAB dynamic optimization code dynopt. User's guide, KIRP FCHPT STU Bratislava, Slovak Republic, Technical Report.

Hull D (2003) Optimal Control Theory for Applications, ser. Mechanical Engineering Series. Springer.

Javinsky A, Kadlec H (1970) Optimal Control of a Continuous Flow Stirred Tank Chemical Reactor. AlChE Journal. 916-924.

Kim HJ, Lee MH, Han C, Chang KS (1998) TimeOptimal control of MMA-MA copolymerization in a CSTR for grade change. Korean Journal of Chemical Engineering. 15(1): 45-50.

Lyuben L (2007) Chemical Reactor Design and Control. John Wiley \& Sons. Inc., Hoboken, New Jersey, USA.

Oravec J, Bakošová M (2012) PIDDESIGN - Software for PID Control Education. In IFAC Conference on Advances in PID Control. 2(1): 691-696.

Pathak K, Markana A, Parekh N (2010) Optimal control of CSTR. Electroanalytical Chemistry. 3: 199-296.

Shakib Joo AD (2013) A Comparison of Different Control Design Methods for the Linearized CSTR Temperature Model. Journal of Electrical and Computer Engineering Innovations. 1(2): 107-114. 